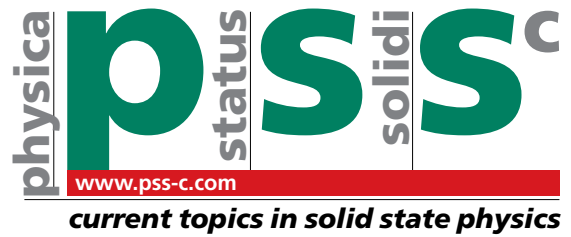

\title{
Plasma immersion ion implantation with auxiliary heating: application to SS304 stainless steel
}

\author{
M. Ueda ${ }^{*, 1}$, A. S. Geraldo ${ }^{1}$, C. B. Mello ${ }^{1}$, and C. M. Lepienski ${ }^{2}$ \\ ${ }^{1}$ Associated Laboratory of Plasma, National Institute for Space Research, S. J.Campos, S. Paulo, Brazil \\ ${ }^{2}$ Department of Physics, Federal University of Paraná, Brazil
}

Received 17 August 2007, revised 25 October 2007, accepted 26 October 2007

Published online 12 March 2008

PACS 52.77.Dq, 62.20.Qp, 68.47.De

* Corresponding author: e-mail ueda@plasma.inpe.br, Phone: +51 123945 6676, Fax: +51 1239456710

In the present experiment, we heated the sample holding fixture using a shielded resistive wire wound around it and the SS samples were subjected to nitrogen glow discharge plasma PIII with moderate voltages of $10 \mathrm{kV}$, in different temperatures $\left(250{ }^{\circ} \mathrm{C}, 270{ }^{\circ} \mathrm{C}, 350{ }^{\circ} \mathrm{C}\right.$ and $\left.390{ }^{\circ} \mathrm{C}\right)$. Then, we compared them to the samples obtained by PIII in which the final temperature of $350{ }^{\circ} \mathrm{C}$ was reached, solely by the bombardment of accelerated ions. X-ray diffraction results indicated a much higher efficiency of auxiliary heated PIII mode com- pared to the ordinary PIII. Very prominent $\gamma_{\mathrm{N}}$ peaks were observed for the first mode, indicating large concentration of nitrogen in thick layers, confirmed by the nitrogen profiles measured by GDOS technique. Improved mechanical and tribological properties were obtained for SS304 samples treated by the PIII with auxiliary heating, more than for ordinary PIII. Corrosion resistance of treated samples was maintained or it was slightly lower compared to the reference sample.
1 Introduction In order to achieve improved surface in components with high reliability required by the tool or metallurgical industries by means of Plasma Immersion Ion Implantation (PIII), it is necessary to obtain quite thick treated layers (order of few to tens of $\mu \mathrm{m}$ ) with reasonable thickness uniformity. One effective way to achieve such a thick nitrogen rich layer in SS304 steel is to run PIII process in high temperatures $[1,2]$, but limited to values lower than $500^{\circ} \mathrm{C}$ to avoid the formation of $\mathrm{CrN}$ which could reduce the corrosion resistance of the stainless steel. Temperatures in the range of $350{ }^{\circ} \mathrm{C}$ to $450{ }^{\circ} \mathrm{C}$ which are effective to induce high thermal diffusion in steels, hence to achieve thick treated layers in SS304, are easily assessed by high power PIII systems. However, treating real industrial components in the batch mode often requires starting the PIII operation with much lower voltages than the ones used in the final operational settings, to avoid arcing [3, 4]. Hence, more than an hour can be lost in this "pre-treatment mode", typically, which can not be afforded in a real industrial PIII operation. Also, in low power PIII systems, such useful temperatures may not be reached solely by the bombardment of the surface of the samples or workpieces by the accelerated ions.
Previously, we used the auxiliary heating of the samples simultaneously with the high voltage pulses, in an experiment with nitrogen PIII applied to Ti6Al4V samples, in the temperature range of $500{ }^{\circ} \mathrm{C}$ to $800{ }^{\circ} \mathrm{C}[5,6]$. For that purpose, we have developed samples support with resistance heating inside (direct heating), in contrast with the technique used by other authors [7] who heated the entire PIII chamber (radiative heating).

In our present experiment, we heated the sample holding fixture with a shielded resistive wire wound properly around it and with protection to the ion bombardment. The SS304 samples were subjected to nitrogen glow discharge plasma PIII with relatively low voltages of $10 \mathrm{kV}$ at maximum, in different temperatures. We also treated the SS samples by the traditional PIII method, increasing slowly the high voltage pulse intensities, from 8 at the beginning to $16 \mathrm{kV}$ at the end of processing, reaching temperatures of up to $350{ }^{\circ} \mathrm{C}$. These modes of treatment were compared with respect to nitrogen implantation profiles, X-ray diffraction, tribology and corrosion resistance and mechanical properties. 


\section{Experimental}

The experimental set-up of the PIII experiment with auxiliary heating of the sample support is similar to the previously used system shown elsewhere [6]. Here, only the sample support was slightly modified and the heating is acomplished via a Stainless Steel shielded flexible cable with $1.5 \mathrm{~mm}$ external diameter, and internal thin wire isolated with ceramic powder. This rugged structure allowed application of much higher pulse voltage (up to $-10 \mathrm{kV}$ ) compared to previously possible $-5 \mathrm{kV}$ limit. These superior qualities of the heating wire could be essential for effective heating of the real industrial components, to perform high temperature PIII treatments. Our previous experience with industrial components indicated a frequent need of very localized heating in large size, massive workpieces in which the ordinary heating by ion bombardment was not sufficient or inadequate, in order to reach high diffusion conditions where necessary. We hope that our present method could overcome this difficulty.

Table 1 PIII treatment conditions with and without auxiliary heating.

\begin{tabular}{|c|c|c|c|c|}
\hline Cases & $\begin{array}{c}\text { Treatment } \\
\text { Time }(\mathrm{h})\end{array}$ & $\begin{array}{c}\text { High Voltage } \\
(\mathrm{kV})\end{array}$ & $\begin{array}{c}\text { Temperature } \\
\left({ }^{\circ} \mathrm{C}\right)\end{array}$ & $\begin{array}{c}\text { Auxiliary } \\
\text { Heating }\end{array}$ \\
\hline 1 & 2 & $5-6.5$ & 270 & with \\
\hline 2 & 4 & $5-9.5$ & 270 & with \\
\hline 3 & 10 & $5-9.5$ & 270 & with \\
\hline 4 & 2.5 & $5.5-10$ & 390 & with \\
\hline 5 & 4 & 10 & 390 & with \\
\hline 6 & 10 & 10 & 390 & with \\
\hline 7 & 4 & $5.5-10$ & 390 & with \\
\hline 8 & 2 & $8-16$ & 350 & without \\
\hline 9 & 2 & $8-16$ & 350 & without \\
\hline 10 & 2 & $8-16$ & 350 & without \\
\hline 11 & 2 & $5-6$ & 350 & with \\
\hline
\end{tabular}

The conditions of nitrogen PIII applied to the SS304 samples with auxiliary heating are listed on Table 1 above. High voltage could not be fixed to single values but was varied monotonically, because of mild arcings that would occur otherwise, except for cases 5 and 6 , which were performed last. Treatments without auxiliary heating were carried out starting at $8 \mathrm{kV}$ and slowly increasing until reaching $16 \mathrm{kV}$, when the achieved temperature was $350{ }^{\circ} \mathrm{C}$.

The temperature was initially measured by three methods, two with infrared pirometers (one with sensitivity starting at $200{ }^{\circ} \mathrm{C}$, another at $250{ }^{\circ} \mathrm{C}$ ), and one with a thermopar. All three agreed quite well, in the respective response regions, but we chose to use the second pirometer for treatments starting with high temperatures because of its better focusing and reliability, and thermopar for monitoring the slowly increasing temperature in the cases without auxiliary heating PIII.

Surface analysis were carried out by X-ray diffaction using Philips 3410 diffractometer in the Seeman-Bolin $2 \theta$ scanning mode. GDOS (Glow Discharge Optical Spectroscopy) was performed with an equipment from LECO, GDS $750 \mathrm{~A}$. For tribological measurements we used the pin-ondisc equipment from CSM-Instruments, model SN-18-313, with $10 \mathrm{~cm} / \mathrm{s}$ linear speed, $4.0 \mathrm{~N}$ applied load, $4 \mathrm{~cm}$ wear track radius, and a $3 \mathrm{~mm}$ diameter $\mathrm{WC}$ ball.

3 Results and discussion In Fig. 1 we can see the time evolution of the temperature for different PIII treatments, either with auxiliary heating or without it.

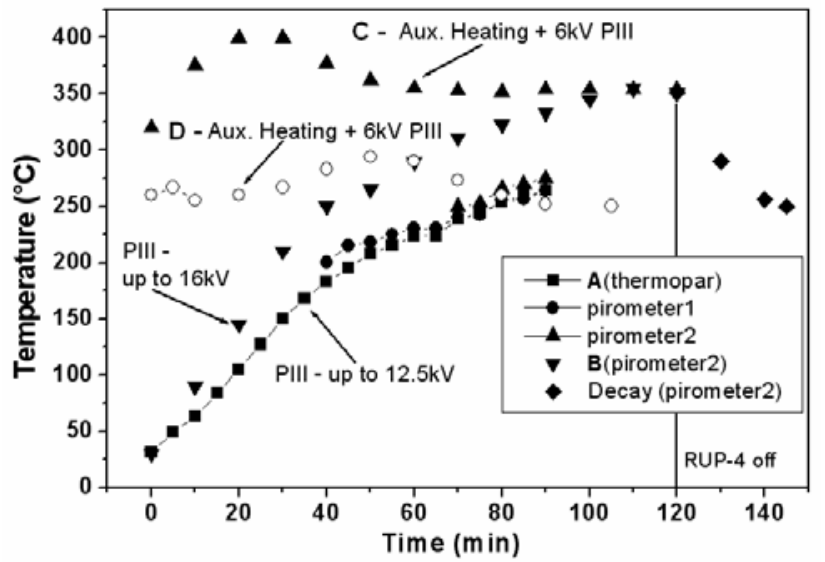

Figure 1 Time evolution of the temperature of the sample support for PIII processings with auxiliary heating and without it.

Curves A and B are typical cases of PIII without auxiliary heating, with such final temperatures of $250-270{ }^{\circ} \mathrm{C}$ and $350-360{ }^{\circ} \mathrm{C}$ being obtained after 90 and $110 \mathrm{~min}$, respectively. The high voltage pulses are increased slowly, starting from $5 \mathrm{kV}$ up to $12.5 \mathrm{kV}$ in the first case and 16 $\mathrm{kV}$ in the second case. To avoid such apparent loss of efficiency to reach highly diffusive regime of implantation, we carried out PIII operations in high temperature regime right from the beginning of the treatment, as in cases C and D of Fig. 1. Although perfectly constant temperature operations are difficult in these cases, high temperature can be imposed from $\mathrm{t}=0 \mathrm{~min}$, as shown by curves $\mathrm{C}$ and $\mathrm{D}$, which is completely different from the ordinary PIII modes of curves A and B. Measurements of temperatures taken with 
thermopar, pirometerl (response above $200{ }^{\circ} \mathrm{C}$ ) and pirometer 2 (above $250{ }^{\circ} \mathrm{C}$ ) are in close agreement above $250{ }^{\circ} \mathrm{C}$. So, thermopar was used for temperatures below $250{ }^{\circ} \mathrm{C}$ and pirometer 2 for temperatures above that value. Connecting the thermopar to the sample holding fixture lowers the final achievable temperature for PIII treatments without auxiliary heating, in low power systems as ours (maximum of $1.5 \mathrm{~kW}$ ). For the PIII treatments used for SS304 surface modifications, we used similar control of temperatures, reaching $270{ }^{\circ} \mathrm{C}, 350{ }^{\circ} \mathrm{C}$ and $390{ }^{\circ} \mathrm{C}$, as shown in Table1.

In Fig. 2 we show the diffractograms corresponding to the treatments which conditions are shown on Table 1. Initially, we discuss the results obtained in PIII processing with auxiliary heating. In Fig. 2 (bottom part), for conditions 1,2 , and 3 , we can see that $\gamma_{\mathrm{N}}$ just starts to appear at the treatment of condition 3 in which $10 \mathrm{~h}$ of PIII with auxiliary heating was applied. For shorter treatments, we could only see either the normal $\gamma$ peaks of Fe or the $\alpha$ peak in the case 1 of $2 \mathrm{~h}$ treatment. The diffractograms of Fig. 2 (middle part), corresponding to conditions 4, 5, 6 and 7, show that the intensities (and widths) of $\gamma_{\mathrm{N}}$ peaks increase with time of treatment. They are the maximum for the sample of case 6 with $10 \mathrm{~h}$ of treatment for which we can even see the third order $\gamma_{\mathrm{N}}$ peak. From another comparison between cases 7 and 5, we can see that the former was less intense than the other, the difference being just the range of energy used, which was smaller for the case 7.

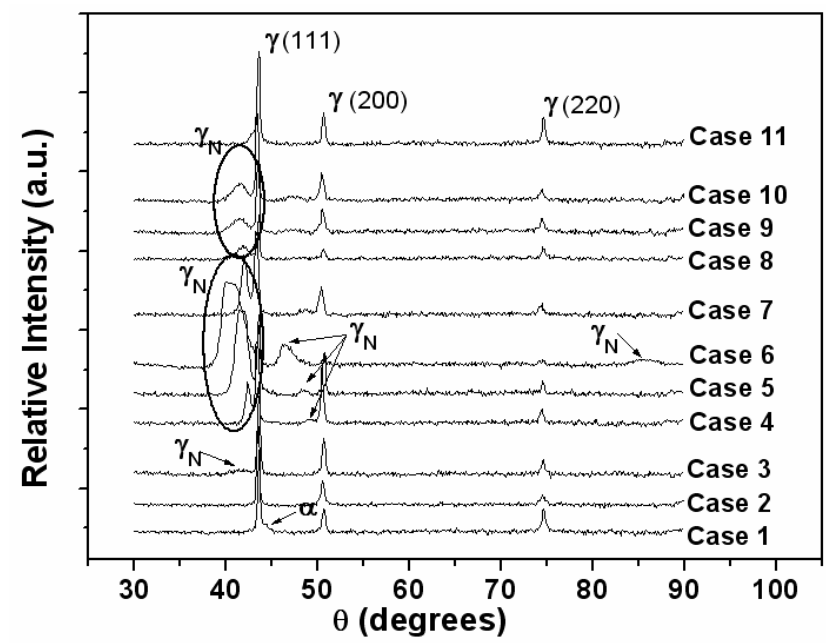

Figure 2 X-ray diffractograms for treatments with conditions of Table 1.

Next, cases 8,9 , and 10 without auxiliary heating will be focused, for which we have the diffractograms shown in Fig. 2 (top part). They present also good $\gamma_{\mathrm{N}}$ peaks, as has been seen often, in various previous works, dealing with nitrogen PIII of SS304. The stated temperature is the final one achieved after $2 \mathrm{~h}$ of treatment. The $\gamma_{\mathrm{N}}$ peaks seen are similar to each other indicating similar implantation of ni- trogen for different positions of the samples treated in the same batch.

We have also included the diffractogram of sample for the case 11, for which the X-ray diffraction is shown in Fig. 2 (toppest), to compare with other cases with GDOS results which will be discussed next.

GDOS results of SS304 samples treated under the conditions shown in Table1 are shown in Fig. 3 (cases1, 2 and 3 ), indicating very thin (about $0.5 \mu \mathrm{m}$ FWHM) nitrogen rich layer close to the surface. The peak concentrations grow significantly $(32 \%)$ with time while the pedestals also increase but they reach only about $1.0 \mu \mathrm{m}$. The results of X-ray diffractograms and the GDOS profiles are in agreement, indicating that for $270{ }^{\circ} \mathrm{C}$ the diffusion effects for nitrogen are very small for SS304 and therefore the obtained treated layers are thin, even after $10 \mathrm{~h}$ of PIII treatment. Consequently the retained doses are small in these cases.

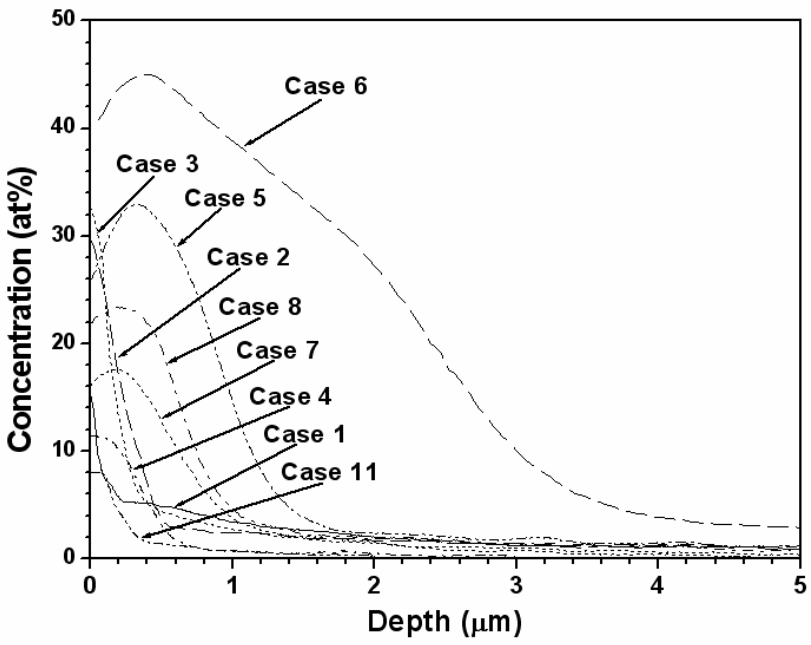

Figure 3 GDOS results for treatments with conditions of Table1.

GDOS nitrogen profiles are quite different for the auxiliary heated PIII treatments with $390{ }^{\circ} \mathrm{C}$, as we will see next. Cases 4, 5, and 6 in Fig. 3 show the nitrogen profiles for increasing treatment time which present increasing retained doses (higher peaks with larger widths). In fact, for case 6 with $10 \mathrm{~h}$ treatment at $390^{\circ} \mathrm{C}$ and $10 \mathrm{kV}$, the peak nitrogen percentage reached $45 \%$, and the deepest reach was near $5 \mu \mathrm{m}$ (with the profile of about $2.5 \mu \mathrm{m}$ FWHM). Here, the X-ray diffractogram results are in good agreement with GDOS results. Comparing cases 7 and 5 , we can see that using pulses with $5.5-10 \mathrm{kV}$ for $4 \mathrm{~h}$ is less effective for nitrogen uptake, than using $10 \mathrm{kV}$ for the whole $4 \mathrm{~h}$.

Among cases 8, 9 and 10, we only have GDOS result for the sample treated as in case 8, without auxiliary heating, which can be seen in Fig. 3. But given that the X-ray diffractions were practically the same for samples of this group, which were from the same batch, we can assume that the nitrogen profiles were similar for them. The measured retained dose is unexpectedly high in this case if we consider that the treatment time was only $2 \mathrm{~h}$, and for most of this time the temperature was less than $270{ }^{\circ} \mathrm{C}$. The 
peak nitrogen concentration was $23 \%$ and its reach was about $1.5 \mu \mathrm{m}$. In this discussion, we are of course taking into account the expected factor of 5 increase in the retained dose for the $10 \mathrm{~h}$ auxiliary heated case, compared to the treatment of $2 \mathrm{~h}$ without auxiliary heating. Furthermore, other up-to-date results based on AES (Auger Electron Spectroscopy) analysis indicated that for $5 \mathrm{~h}$ and $8 \mathrm{~h}$ treatments without auxiliary heating (both not continuous treatment, $2+3 \mathrm{~h}$, and $2+3+3 \mathrm{~h}$, respectively), the nitrogen rich layer did increase almost nothing, compared to the $2 \mathrm{~h}$ treatment case. This is supposed to be due to the sputtering effects. We should also point out that the $10 \mathrm{~h}$ treatment with auxiliary heating is also conducted in steps of 4 $+3+3 \mathrm{~h}$. Here the effects of sputtering was outcomed by the diffusion process.

Curves of friction coefficient $\mu$ for surfaces of SS304 treated under a few different conditions in Table 1 are shown in Fig. 4. The standard (reference) sample presented a curve starting near 0.7 and a peak reaching 1.2 at $1.2 \times 10^{3}$ cycles, slowly decreasing to a constant value of 0.75 , until $10^{4}$ cycles. The curve for sample of case 1 , starts much below, near 0.1 and shows also a peak near $1.5 \times 10^{3}$ cycles, as in the standard case. Then it levels off to a $\mu$ of about 0.65 . Indeed, this was a PIII treatment with relatively low temperature, low energy and short treatment time, hence with low retained dose, which led to a $\mu$ with similar behavior to the standard sample, although at low values for the whole observed cycles. The $\mu$ curve corresponding to case 3 , with longer treatment time showed a lower peak near $2.3 \times 10^{3}$ and then levelled off at 0.8 , indicating a worsened friction behavior, maybe due to a rougher surface after the treatment. Other curves of friction coefficient show similar behavior, starting very low, between 0.1 and 0.2 , and quickly increasing until $1 \times 10^{3}$ cycles, then levelling off to respective values, ranging from 0.45 to 0.7 . All of these samples showed $\mu$ curves below the standard one, including the one with highest retained dose (case 6).

Corrosion tests performed in the SS304 samples treated in the conditions shown in Table 1 presented as high resistance to corrosion as the standard or slightly lower, not compromising the stainless character of these steel alloy. Hardness was enhanced by up to 2.7 times, as seen by nanoindentation tests.

4 Conclusion Samples of SS304 were implanted either by auxiliary heated or ordinary nitrogen PIII. In the first mode of treatment, very prominent $\gamma_{\mathrm{N}}$ peaks were observed for the cases with near constant temperatures of $390{ }^{\circ} \mathrm{C}$ for $10 \mathrm{~h}$, and GDOS nitrogen profiles showed very high retained dose (r.d.) with peak concentration of $45 \%$ and a maximum nitrogen reach of about $4-5 \mu \mathrm{m}$, due to a strong thermal diffusion of the nitrogen inside the steel. In this case, sputtering of the surface being implanted was outcomed by the diffusion effect which resulted in the insertion of the nitrogen atoms inward, quicker than their loss.

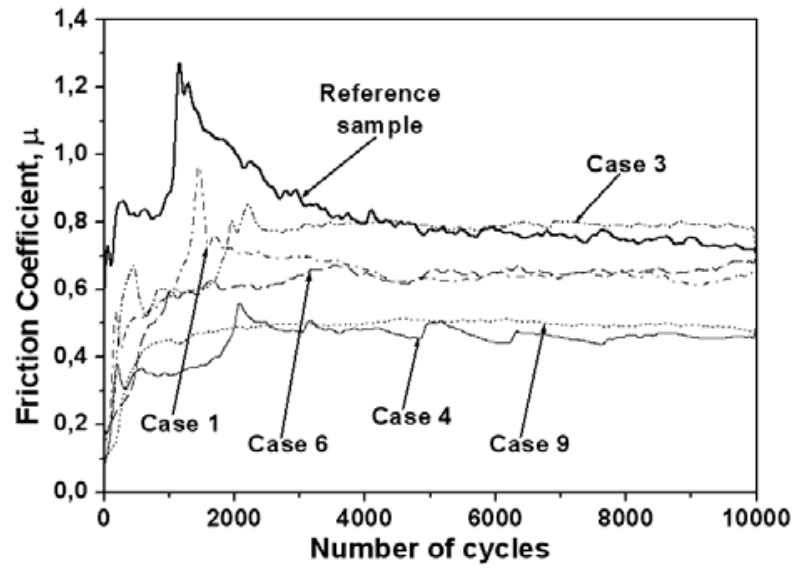

Figure 4 Curves of coefficient of friction for samples with different PIII treatment conditions and for the reference sample.

Meanwhile, in the ordinary PIII with heating due to only the bombarding ions, the reached peak nitrogen concentration was only about $25 \%$ with a maximum reach of $1.5 \mu \mathrm{m}$, hence with much less r.d. In this second mode performed for only $2 \mathrm{~h}$ and at $350{ }^{\circ} \mathrm{C}, \gamma_{\mathrm{N}}$ peaks were also seen but not as intense as for the first mode. For treatments of 5 and $8 \mathrm{~h}$ in this mode, the nitrogen rich layer was not increased at all, most probably due to the sputtering effects, although they were performed in 2 and 3 steps (not continuously, which is also the case with auxiliary heating). Friction coefficients of the samples treated by the both modes were reduced to values lower than 0.8 presented by the reference sample (r.s), in particular compared to the peaked value of 1.2 seen at $1.2 \times 10^{3}$ cycles for the r.s. Corrosion resistance was kept as high as in the untreated sample. Mechanical properties were improved for the both methods. These results on corrosion, mechanical properties and Auger analysis will be discussed in detail in another paper under preparation.

Acknowledgements Supported by FAPESP, CNPq, CAPES and MCT, Brazil.

\section{References}

[1] G. A. Collins, R. Hutchings, K. T. Short, J. Tendys, X. Li, and M. Samandi, Surf. Coat. Technol. 74/75, 417 (1995).

[2] C. Blawert, H. Kalvelage, B. L. Mordike, G. A. Collins et al., Surf. Coat. Technol. 136, 181 (2001).

[3] M. Ueda, L. A. Berni, R. M. Castro et al., Surf. Coat. Technol. 156, 71 (2002).

[4] M. Ueda, L. A. Berni, and R. M. Castro, Surf. Coat. Technol. 200, 517 (2005).

[5] M. Ueda, M. M. Silva, C. M. Lepienski et al., Surf. Coat. Technol. 201, 4953 (2007).

[6] M. M. Silva, M. Ueda, L. Pichon et al., Nucl. Instrum. Methods Phys. Res. B 257, 722 (2007).

[7] V. Fouquet, L. Pichon, A. Straboni, and M. Drouet, Suf. Coat. Technol. 186, 34 (2004). 